\title{
Variable Interval Responding Maintained by Intravenous Codeine and Ethanol Injections in the Rhesus Monkey ${ }^{1}$
}

\author{
JOHN M. CARNEY, ${ }^{2}$ MARK E. LLEWELLYN ${ }^{3}$ AND JAMES H. WOODS ${ }^{4}$ \\ Departments of Pharmacology and Psychology, University of Michigan, Ann Arbor, MI 48109
}

(Received 21 June 1976)

\begin{abstract}
CARNEY, J. M., M. E. LLEWELLYN AND J. H. WOODS. Variable interval responding maintained by intravenous codeine and ethanol injections in the rhesus monkey. PHARMAC. BIOCHEM. BEHAV. 5(5) 577-582, 1976. - Rhesus monkeys were trained to respond under a variable interval $2 \mathrm{~min}$ schedule for codeine or ethanol injections. Both codeine and ethanol were effective in the initiation of variable-interval responding; responding was maintained over a range of codeine $(0.003-1.0 \mathrm{mg} / \mathrm{kg} /$ injection) and ethanol doses $(32.0-560 \mathrm{mg} / \mathrm{kg} /$ injection). Maximum rates of responding were obtained at the $0.01 \mathrm{mg} / \mathrm{kg} / \mathrm{injection}$ codeine dose $(0.14$ responses $/ \mathrm{sec})$ and at the $180 \mathrm{mg} / \mathrm{kg} /$ injection codeine dose $(0.19$ responses/sec). Rates of responsing were bitonic functions of the reinforcer dose for both codeine and ethanol; maximum rates were obtained at intermediate doses and lower rates occurred at the extremes of the dose range. Both codeine and ethanol showed within-session decreases in responding across the range of reinforcer doses. Codeine-reinforced responding declined in rate within the one-hour session without a similar change in the frequency of drug injection; in contrast, both ethanol-reinforced responding and the frequency of ethanol injections declined within each session across a range of doses. Increasing or decreasing the codeine dose half-way through the one-hour session resulted in increases or decreases in codeine responding compared to controls. These data indicate that the progressive decline in codeine-reinforced responding is not the result of a generalized disruption of responding.
\end{abstract}

Variable interval Schedule of reinforcement Self-administration Codeine Ethanol

THE SCHEDULE of reinforcement has been shown to be a primary determinant of the rate and pattern of operant responding across a range of different reinforcers $[1,5,6$, $11,12,14,16,18]$. Under schedules of food or drug reinforcement in which the reinforcer is delivered after a fixed number $(n)$ of responses (fixed-ratio $n, F R n$ ), reinforcement is followed by a period of time in which no responses are emitted and this period is followed by responding at a relatively constant, high rate. Downs and Woods [5] reported that during each session thesus monkeys exhibited a progressive decline in FR 30 responding maintained by codeine injections. Responding occurred at a relatively high rate in the initial portion of each session and progressively declined during the session to a relatively low rate of responding in the terminal portions of the session. As the codeine reinforcer dose was increased across blocks of sessions from $0.1-1.0 \mathrm{mg} / \mathrm{kg} /$ injection, the degree of negative acceleration increased. Negatively accelerated patterns of responding also have been described for ethanol, d-amphetamine, cocaine, and food reinforcement $[7,15,17,19]$.
In the majority of the self-administration studies in which negative acceleration was observed, drug reinforcement was available under FR schedules. A feature of FR schedules is that the rate of responding determines the frequency of reinforcer delivery. Thus, a negatively accelerated pattern of FR responding would result in a negatively accelerated pattern of drug injections. In contrast to FR schedules, under a variable interval (VI) schedule of reinforcement, responses are reinforced on the basis of the time since the last reinforcement [3]. For this reason, the frequency of reinforcer delivery under a VI schedule is relatively independent of the rate of responding across a wide range of response rates. The first purpose of the present study, therefore, was to determine if the dose-related negative acceleration of responding observed for ethanol and codeine reinforcement under FR schedules would also occur under a VI schedule of reinforcement. The second purpose was to quantitatively describe the relationship between the reinforcer dose of codeine or ethanol and the degree of negative acceleration observed. The third purpose was to determine the effects of changing

\footnotetext{
${ }^{1}$ This research was supported in part by USPHS Grant DA00154 and GM00198.

${ }^{2}$ Predoctoral trainee in Pharmacology supported by USPHS Grant GM00198. Present address: Department of Pharmacology, MCV Station 726, Medical College of Virginia, Richmond, VA 23298.

${ }^{3}$ Predoctoral trainee in Psychology supported by an Addiction Research Foundation of Ontario Fellowship.

${ }^{4}$ Send reprint requests to: Dr. James H. Woods, Department of Pharmacology, University of Michigan Medical School, Ann Arbor, MI 48104.
} 
the magnitude of the codeine reinforcer dose midway through the session, since it is possible that responding declined due to either a generalized behavioral disruption caused by cumulated codeine doses or due to some other effect, such as the development of acute tolerance to the behavioral effect of codeine.

\section{METHOD}

\section{Animals and Equipment}

Five rhesus monkeys (Macaca mulatta) with no prior experimental histories were used. The animals weighed approximately $4 \mathrm{~kg}$ at the beginning of the study and were housed in individual cages. They were fed a standard primate diet to which the antitubercular drug isoniazid had been added $(608.3 \mathrm{~g} /$ ton $)$. Throughout the study, animals were fed ad lib and had free access to water in their home cages. Prior to the start of the experiments, monkeys were prepared with chronic intravenous catheters under ketamine anesthesia $(30 \mathrm{mg} / \mathrm{kg}$, IM) similar to the method of Deneau, et al. [4]. Each animal wore a leather vest to protect the catheter which passed under the skin and exited from the center of the animal's back. Animals were placed in primate restraining chairs and experiments were conducted in a wooden sound-attenuating cubicle, similar in design to that described by Downs and Woods [5]. Drug solutions were delivered through the indwelling catheter by means of peristaltic pump (Watson, Marlow Limited, Falmouth, Cornwall, England; No. MHRK 55). Injection duration was $15 \mathrm{sec}$ and the dose per injection was varied by altering drug concentration and the volume of the solution delivered.

\section{Procedure}

Three monkeys were trained to press a lever in the presence of a green light to receive an injection of codeine $(0.1 \mathrm{mg} / \mathrm{kg} /$ injection $)$ and the other two monkeys were trained to respond in the presence of a green stimulus light for ethanol injections $(100 \mathrm{mg} / \mathrm{kg} /$ injection $)$. The animals were initially trained under a VI $15-\mathrm{sec}$ schedule of reinforcement. Under this schedule, drug injections were delivered contingent on the first response after a variable time interval, since the termination of the last drug reinforcement. After several sessions under the FI 15-sec schedule, the interval value was gradually increased over a number of sessions to the terminal VI 2-min value. Under the VI 2-min schedule the time interval between each available injection varied between 5 and $455 \mathrm{sec}$. During drug injections, the green light was turned off and a red light was turned on for the duration of the injection. Responses during drug injections had no programmed consequences. Following a period of approximately 20 days at the $0.1 \mathrm{mg} / \mathrm{kg} /$ injection codeine and the $100 \mathrm{mg} / \mathrm{kg} /$ injection ethanol doses, animals were tested for 10 days at each of a range of codeine $(0.003-1.0 \mathrm{mg} / \mathrm{kg} /$ injection $)$ and ethanol (32.0-560.0 mg/kg/injection) doses. Only the last 5 days at each dose were used in calculations. Animals were tested in an increasing-dose sequence and then returned to the baseline dose $(0.1 \mathrm{mg} / \mathrm{kg} /$ injection, codeine; 100 $\mathrm{mg} / \mathrm{kg} /$ injection ethanol.)

Each 1-hr session was divided into six 10-min segments and the number of responses and drug reinforcements in each segment were separately recorded. The mean overall VI response rates were calculated and the total number of drug reinforcements in each session were recorded. A quarter-life value for VI responding and drug injections was calculated by an adaptation of the method of Gollub [8]. In this case, responses were cumulated across successive sixths of the session and quarter-life was calculated in terms of the amount of time, expressed as a percentage of the 1-hr session, required for the emission of the first one-quarter of all responses. A similar measure was calculated for drug injections.

In the second phase of the experiment, the effects of changing the codeine dose half-way through the session were examined. The basic VI 2 -min schedule was in effect as described above. In addition, a blue stimulus light was illuminated to signal the second half of the session. The blue light remained on in the chamber during both the VI 2-min and drug injection components in the second half-hour of the session. The standard $0.1 \mathrm{mg} / \mathrm{kg} /$ injection codeine dose was always available in the first half of the session. The dose in the second half of the session was one of four possible doses: saline, $0.01,0.1$, and $1.0 \mathrm{mg} / \mathrm{kg} /$ injection. Each animal was tested for 10 sessions at each of the four doses; only the last 5 sessions were used in calculations. Doses in the first and second halves of the session were separately delivered by means of a Y-connector attached to the indwelling catheter (Becton Dickenson, No. 3091).

\section{Drugs}

Ethyl alcohol (ethanol) and codeine phosphate were dissolved in $0.9 \%$ saline. Codeine doses refer to the salt.

\section{RESULTS}

Rates of responding under the VI 2-min schedule were bitonic functions of the reinforcer dose for both codeine and ethanol (Fig. 1). The maximum rate of codeine reinforced responding $(0.14$ responses/sec $)$ was maintained by the $0.01 \mathrm{mg} / \mathrm{kg} /$ injection dose and the maximum rate of ethanol reinforced responding $(0.19$ responses/sec) was maintained by the $180 \mathrm{mg} / \mathrm{kg} /$ injection dose. Higher or lower reinforcer doses resulted in lower rates of responding. The total amount of drug self-administered in a 1-hr session

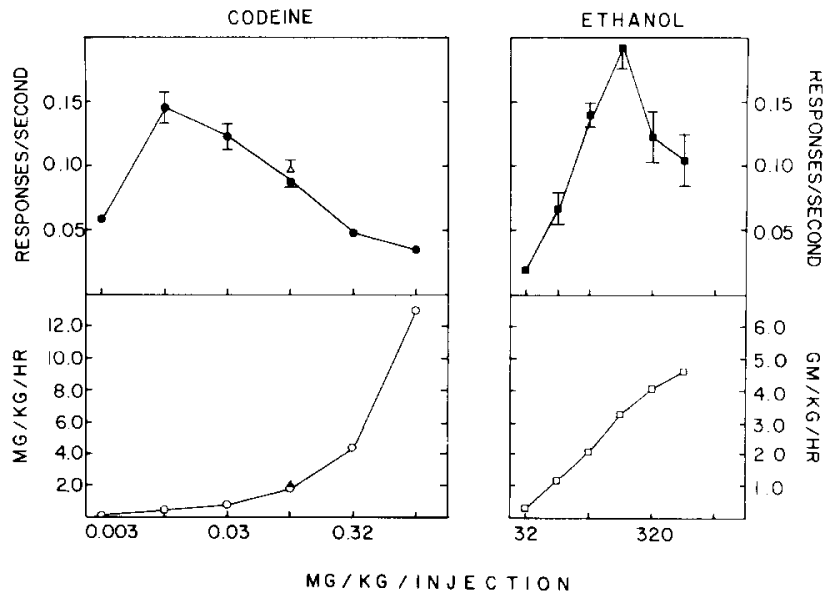

FIG. 1. Response rates (responses/second; upper graph) and drug intake (amount of drug $/ \mathrm{kg} / \mathrm{hr}$; lower graph) at the various codeine and ethanol reinforcer doses on a VI 2 -min schedule. Each point is the mean ( $\pm 1 \mathrm{SE}$ ) for fifteen observations (5/animal) at each codeine dose and 10 observations (5/animal) at each ethanol dose. Replication of the baseline performance under the $0.1 \mathrm{mg} / \mathrm{kg}$ / injection dose of codeine is included $(\wedge, \wedge)$. 


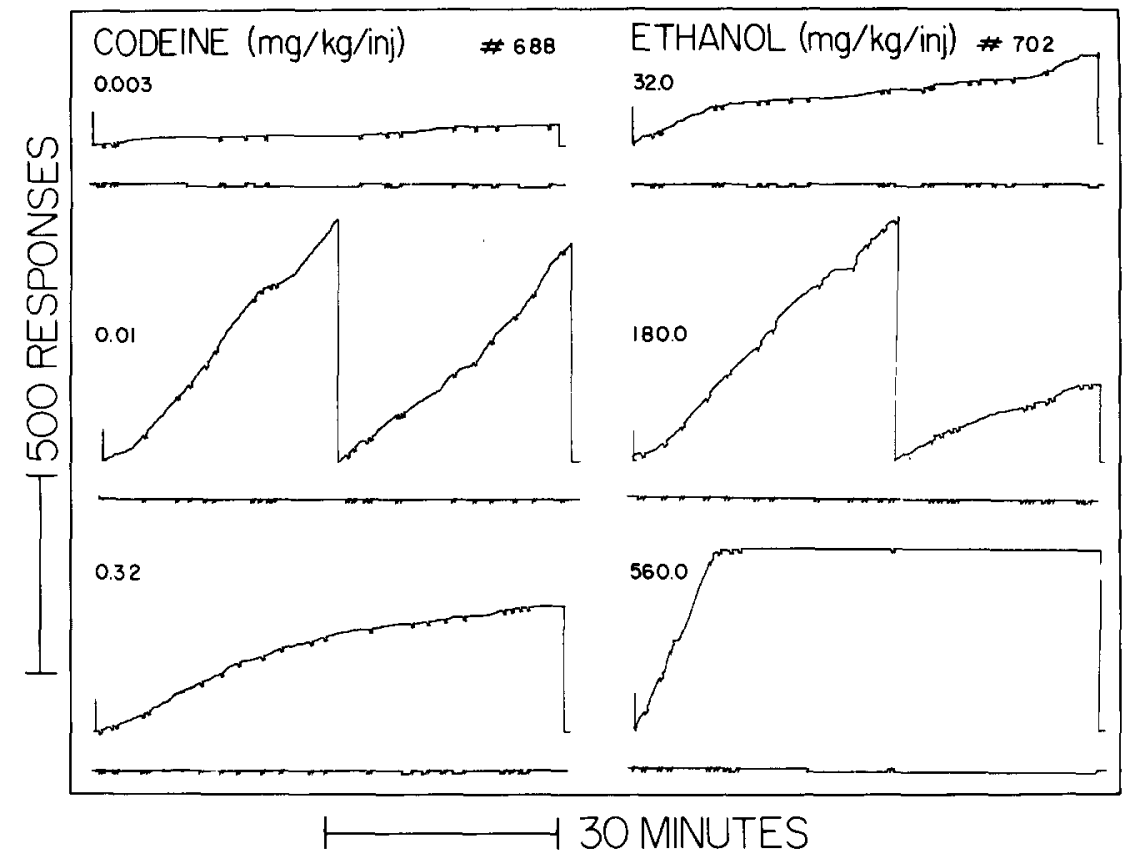

FIG. 2. Cumulative records of performance in individual sessions across a range of codeine and ethanol reinforcer doses in monkeys Nos. 688 (codeine) and 702 (ethanol). Each lever press response moved the response pen (upper pen) upwards one step while the paper moved from right to left at a constant speed. A deflection of the response pen indicated the delivery of a drug injection. The response pen automatically reset after about 500 responses and was reset after the session terminated. A downward deflection of the lower pen in each record indicated the availability of drug reinforcement, contingent on a lever press response. When the reinforcement was collected, the lower pen returned to its normal position.

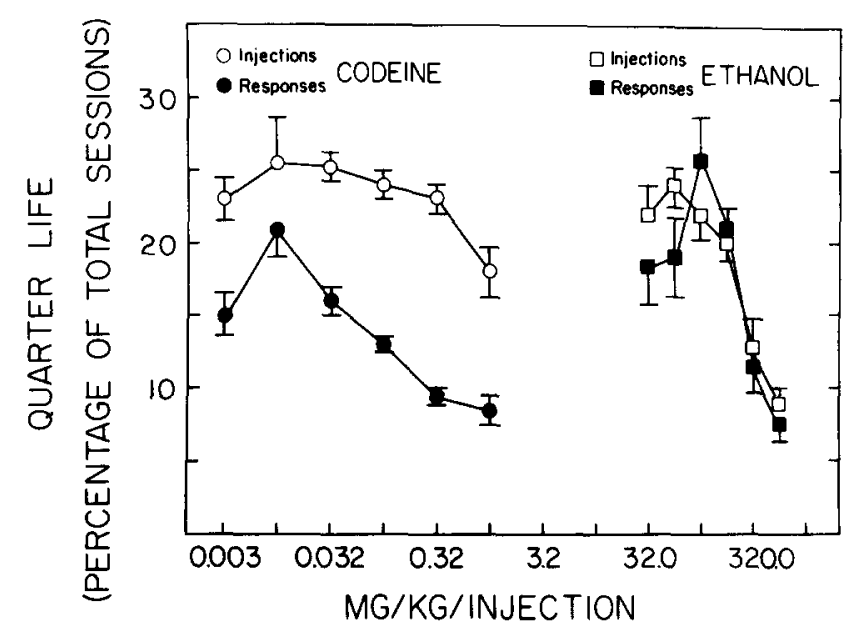

FIG. 3. Effects of various reinforcer doses on quarter-life values for drug injection and VI responding. Quarter-life values are expressed as a percentage of the total 1-hr session. Each codeine point is the mean ( $\pm 1 \mathrm{SE}$ ) for 15 observations (5/animal) at each codeine dose and 10 observations (5/animal) at each ethanol dose.

was a power function of the codeine dose and a log function of the ethanol dose.

In general, both codeine and ethanol showed negatively accelerated patterns of responding within individual sessions (Figs. 2 and 3). That is, more responses were emitted early in the session than were emitted in the terminal segments of the session. Relatively few responses were emitted during codeine injections at any of the doses tested; in contrast, responding during ethanol injection frequently occurred.

Calculation of the quarter-life values for both responses and drug injections provided quantitative estimates of the degree of negative acceleration at each of the various reinforcer doses (Fig. 3). The quarter-life values for both codeine and ethanol responding were bitonic functions of the reinforcer dose. The $0.01 \mathrm{mg} / \mathrm{kg} /$ injection codeine and $100 \mathrm{mg} / \mathrm{kg} /$ injection ethanol doses resulted in the smallest degree of negative acceleration or showed none at all. Higher or lower doses resulted in greater degrees of negative acceleration, indicated by decreases in the quarter-life values for responses. The functions relating response rate to reinforcer dose were similar for the two drugs. A difference between the drugs was observed in terms of the distribution of injections within the session. Codeine injections were delivered at a roughly constant rate throughout the session at doses between 0.003 and $0.32 \mathrm{mg} / \mathrm{kg} /$ injection, indicated by quarter-life values for injections of approximately $25 \%$ (Fig. 3). In contrast, the ethanol injection quarter-life values were also bitonic functions of the reinforcer dose and closely paralleled the response rate quarter-life curve.

Observation of the animals at the end of the session further demonstrated differences in the behavioral effects of the two drugs. Monkeys that self-administered codeine appeared normal when examined, regardless of the dose. On the other hand, animals that self-administered ethanol exhibited a number of gross behavioral effects at the end of 


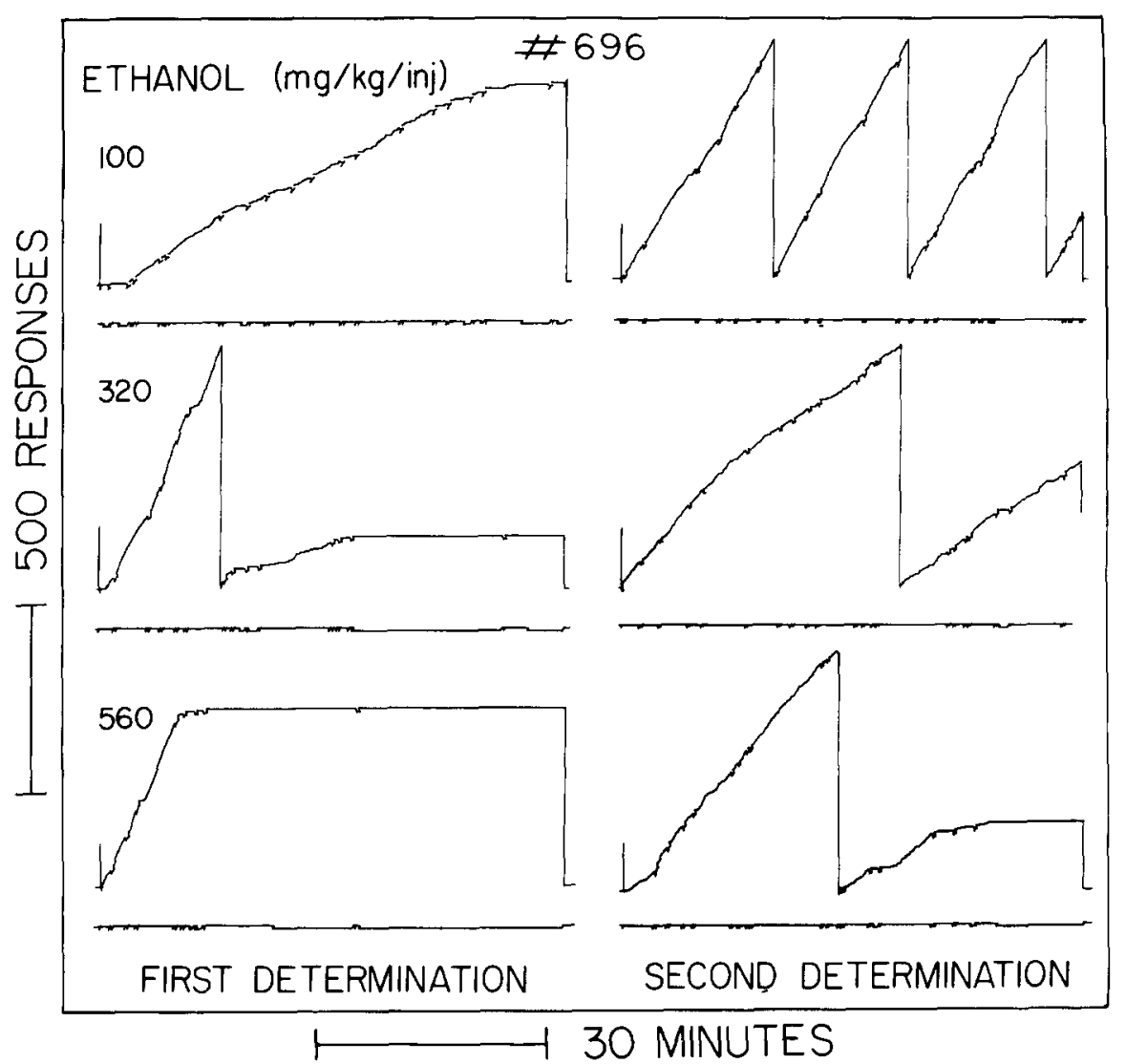

FIG. 4. Cumulative records of performance in individual sessions at 3 ethanol doses on first and second determination for monkey No. 696. See Fig. 2 for an explanation of the cumulative record. Animals were exposed to a range of ethanol doses for 10 days at each dose and then the doses shown were redetermined. Each dose was tested for 10 days and doses were tested in an increasing order.

the 1-hr session. At the $180.0,320.0$ and $560.0 \mathrm{mg} / \mathrm{kg} /$ injection ethanol doses, monkeys were ataxic and had impaired corneal reflexes. At the $560.0 \mathrm{mg} / \mathrm{kg} /$ injection dose, animals frequently self-administered sufficient quantities of ethanol to abolish the corneal reflex and to produce a state of unconsciousness for several hours.

Redetermination of the $0.1 \mathrm{mg} / \mathrm{kg} /$ injection codeine dose after completion of the codeine reinforcer-dose series resulted in response rates and patterns of responding similar to those obtained in the original determinations. In contrast, a partial redetermination of the ethanol reinforcer dose series resulted in increases in responding at each of the doses tested, compared to the values obtained on first determination (Fig. 4). In addition, the degree of negative acceleration was less on second determination.

The effects of changing the codeine dose half-way through the session are shown in Fig. 5. When the standard codeine dose $(0.1 \mathrm{mg} / \mathrm{kg} /$ injection $)$ was available throughout the session, VI responses were distributed in a negatively accelerated pattern; the greatest number of responses were emitted in the first 10 -min segment of the session and responding declined throughout the session. When the dose in the second half of the session was saline there was a decrease in responding throughout the second half compared to the standard curve. A similar decrease in responding in the second half was seen when the dose was $1.0 \mathrm{mg} / \mathrm{kg} /$ injection. However, when the dose in the second half was $0.01 \mathrm{mg} / \mathrm{kg} /$ injection there was a transient increase in responding, indicating that the reduced rate of codeine responding was not necessarily due to a generalized suppression of behavior by cumulated codeine doses.

\section{DISCUSSION}

The present study demonstrated that both codeine and ethanol can function as reinforcing stimuli in the acquisition and maintenance of responding under a VI schedule of reinforcement. Moreover, codeine and ethanol maintained roughly similar maximum rates of responding. The dose effect curve for codeine-reinforced responding under the VI 2-min schedule was similar to that reported by Downs and Woods [5] for codeine under a FR 30 schedule of reinforcement. In addition, the data obtained for the distribution of VI responding for codeine were consistent with the results of Downs and Woods [5] for codeine under a FR 30 schedule.

The data obtained in the present study suggest that tolerance to the behavioral effects of ethanol can develop under a schedule of once-daily sessions of ethanol selfadministration. While the degree of ethanol tolerance was not directly determined, comparison of the within-session patterns of responding and the total ethanol intake per session on first and second determination showed that after a history of ethanol self-administration monkeys injected substantially greater amounts of ethanol and that at all 


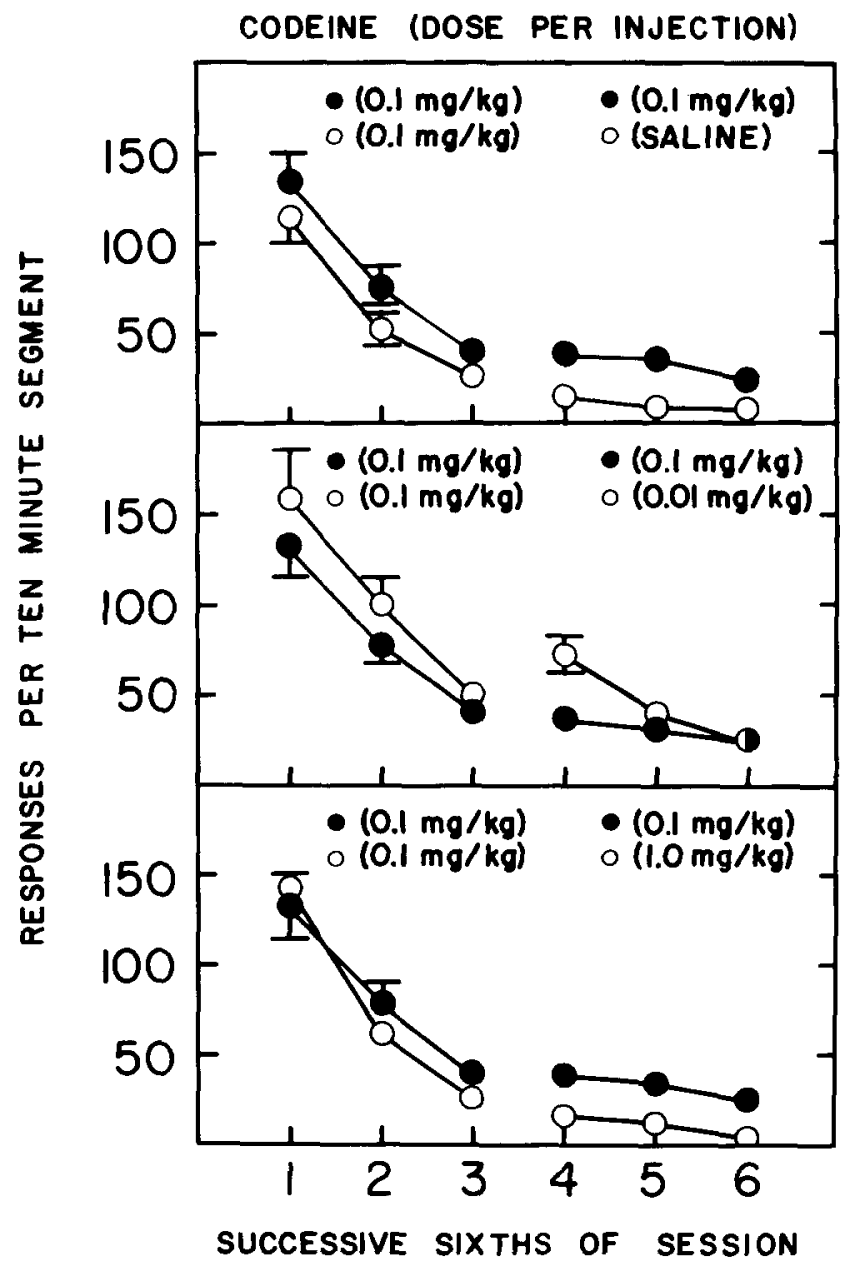

doses the degree of within-session decline in VI responding was less on second determination, compared to the first exposure. None of the monkeys showed any evidence of physical dependence development throughout the course of the study. Previous studies have shown that tolerance to ethanol and various sedative-hypnotics can develop over the course of days to a few weeks [10]. Also, it has been reported that while tolerance always accompanies physical dependence, tolerance can be produced independent of physical dependence [10]. In the present study, daily self-administration of relatively high doses of ethanol appeared to result in the development of tolerance to some of the behavioral effects of ethanol in the absence of physical dependence. The results of the present study also indicate that, at least in the case of codeine, it is possible to demonstrate a negatively accelerated pattern of VI responding in the absence of a change in the frequency of injections across a range of reinforcer doses. Such a separation of the pattern of responding from the pattern of drug injections is not possible under a FR schedule of reinforcement because the frequency of injections is directly related to the rate of FR responding. The negatively accelerated pattern of codeine-reinforced responding was not the result of a codeine-induced suppression of responding, since both increases and decreases in responding could be produced by changing the codeine dose half-way through the session. Under a multiple FR 30 schedule of food and codeine reinforcement, Carney and Woods [2] found that codeine reinforced responding was negatively accelerated across a range of doses and that food-reinforced responding which followed codeine self-administration was unaffected. Thus, it appears that negatively accelerated patterns of drugreinforced responding can occur in the absence of a generalized disruption of responding.
FIG. 5. Effects of changing the codeine reinforcer dose half-way through the 1-hr session on VI responding in successive sixths of the session (10-min segments). For reference, responding in successive six ths of the session when the standard $0.1 \mathrm{mg} / \mathrm{kg} /$ injection codeine dose was available (closed symbols) throughout the session is plotted in each panel. Conditions in which the dose was changed half-way through the session (open symbols) are shown in each of the panels. In all cases the standard dose was available in the first half of the session. Each point is the mean ( \pm 1 SE) of 15 observations (5/animal) under each of the codeine dose change conditions and when the standard dose was available throughout the session.

\section{REFERENCES}

1. Azrin, N. H., D. F. Hake, W. C. Holz, and W. C. Hutchinson. Motivational aspects of escape from punishment. $J$. exp. Analysis Behav. 8: 31-44, 1965.

2. Carney, J. M. and J. H. Woods. Effects of morphine, codeine and nalox one on food- and codeine-reinforced responding in the rhesus monkey. Fedn Proc. 32: 726, 1973.

3. Catania, A. C. and G. S. Reynolds. A quantitative analysis of the responding maintained by interval schedules of reinforcement. J. exp. Analysis Behav. 11: 327-383, 1968.
4. Deneau, G. A., T. Yanagita and M. H. Seevers. Self-administration of psychoactive substances by the monkey: A measure of psychological dependence. Psychopharmacologia 16: $30-48,1969$.

5. Downs, D. A. and J. H. Woods. Codeine- and cocaine-reinforced responding in rhesus monkeys: effects of dose on response rates under a fixed-ratio schedule. J. Pharmac. exp. Ther. 191: 179-188, 1974. 
6. Ferster, C. B. and B. F. Skinner, Schedules of Reinforcement. New York: Appleton-Century-Crofts, 1957.

7. Goldberg, S. R. Comparable behavior maintained under fixedratio and second-order schedules of food presentation, cocaine injection or $d$-amphetamine injection in the squirrel monkey. J. Pharmac. exp. Ther. 186: 18-30, 1973.

8. Gollub, L. R. The relations among measures of performance of fixed-interval schedules. J. exp. Analysis Behav. 7: 337-343, 1964.

9. Hoffmeister, F. and U. U. Schlichting. Reinforcing properties of some opiates and opioids in rhesus monkeys with histories of cocaine and codeine self-administration. Psychopharmacologia 23: 55-74, 1972.

10. Kalant, H., A. E. LeBlanc and R. J. Gibbins. Tolerance to, and dependence on, some non-opiate psychotropic drugs. Pharmac. Rev. 23: 135-191, 1971.

11. Kelleher, R. T. and W. H. Morse. Determinants of the specificity of behavioral effects of drugs. Ergeb. Physiol. 60: $1-56,1968$

12. McKearney, J. W. Effects of $d$-amphetamine, morphine and chlorpromazine on responding under fixed-interval schedules of food presentation or electric shock presentation. $J$. Pharmac. exp. Ther. 190: 141-153, 1974.
13. Meisch, R. A. and T. Thompson. Ethanol as a reinforcer: Effects of fixed-ratio size and food deprivation. Psychopharmacologia 28: $171-183,1973$.

14. Pickens, R. and T. Thompson. Cocaine-reinforced behavior in rats. J. Pharmac. exp. Ther. 161: 122-129, 1968.

15. Sidman, M. and W. C. Stebbins. Satiation effects under fixed-ratio schedules of reinforcement. J. comp. physiol. Psychol. 47: 114-116, 1954.

16. Valenstein, E. S. Problems of measurement and interpretation with reinforcing brain stimulation. Psychol. Rev. 71:415-437, 1964.

17. Woods, J. H., F. Ikomi and G. Winger. The reinforcing property of ethanol. In: Biological Aspects of Alcohol. Advances in Mental Science III, edited by M. K. Roach, W. McIsaac and P. T. Creaven. Austin; University of Texas Press, pp. 371-387, 1971

18. Woods, J. H. and C. R. Schuster. Opiates as reinforcing stimuli. In: Stimulus Properties of Drugs, edited by T. Thompson and R. Pickens. New York: Appleton-Century-Crofts, pp. $163-175,1971$

19. Yokel, R. A. and R. Pickens. Drug level of $d$ - and l-amphetamine during intravenous self-administration. Psychopharmacologia 34: 255-264, 1974. 